\title{
METODE BUDIDAYA TAUGE DALAM SMART GREEN HOUSE DENGAN SISTEM PENYIRAMAN OTOMATIS
}

\author{
Kevin Arie Sandy ${ }^{1}$, Arnold Aribowo ${ }^{2}$, Alfa Satya Putra ${ }^{3}$, Aditya Rama Mitra ${ }^{4}$ \\ ${ }^{1}$ Fakultas Ilmu Komputer, Universitas Pelita Harapan \\ ${ }^{2}$ Fakultas Ilmu Komputer, Universitas Pelita Harapan \\ ${ }^{3}$ Fakultas Ilmu Komputer, Universitas Pelita Harapan \\ ${ }^{4}$ Fakultas Ilmu Komputer, Universitas Pelita Harapan \\ ${ }^{1}$ kevinas1997@gmail.com, ${ }^{2}$ arnold.aribowo@uph.edu, ${ }^{3}$ alfa.putra@uph.edu, ${ }^{4}$ aditya.mitra@uph.edu
}

\begin{abstract}
There are many techniques to cultivate mung bean sprout, however the process requires many human involvements which can cause problems, such as forgetting to water the mung bean sprout, cutting the tail which must be cut one by one, finding the ideal location, and detecting water leakage.

In this research, mung bean sprout will be grown with an automatic watering system in a Smart Green House system, which is able to monitor the mung bean sprout using technologies such as light, temperature and humidity sensors to determine the ideal place of cultivation, water level sensor to measure remaining water level in the container, and water sensor to detect water leakage from the planting medium.

Arduino Mega 2560 is used as the microcontroller in this system. The sensors and components used in the system includes Light Dependent Resistor GL5506, Water Sensor Funduino, buzzer, Ultrasonic Ping HC-SR04, Humidity and Temperature Sensor DHT11, potentiometer, servo motor, relay with 12 V pump, Knee and Nipple Watering System, and Fogger Head Sprayer.

The system is able to cultivate mung bean sprout with length of 3-5 cm, without losing their color in the process, and can be harvested without tail.
\end{abstract}

Keywords: Arduino, automation, mung bean sprout, watering

\section{Abstrak}

Saat ini, terdapat banyak teknik untuk membudidayakan tauge, namun pada prosesnya masih banyak membutuhkan campur tangan manusia sehingga dapat menimbulkan masalah, seperti lupa melakukan penyiraman, pemotongan ekor tauge yang harus dilakukan satu per satu, menentukan lokasi ideal budidaya, dan mendeteksi adanya kebocoran atau genangan air.

Pada penelitian ini, tauge akan ditanam pada sistem Smart Green House yang telah dibuat untuk memonitor kondisi tauge selama proses budidaya menggunakan berbagai jenis sensor. Sensor pendeteksi cahaya, sensor suhu dan kelembaban digunakan untuk menentukan tempat ideal untuk budidaya. Sensor ketinggian air untuk mengukur sisa air pada tempat penyimpanan air, dan sensor pendeteksi air untuk mendeteksi air yang keluar dari dalam media tanam.

Arduino Mega 2560 digunakan sebagai mikrokontroler pada sistem ini. Sensor dan komponen yang digunakan pada sistem ini antara lain Light Dependent Resistor GL5506, Water Sensor Funduino, buzzer, Ultrasonic Ping HC-SR04, Humidity and Temperature Sensor DHT11, potentiometer, servo motor, relay dengan pompa $12 \mathrm{~V}$, sistem penyiram Knee dan Nipple, dan mata penyiram Fogger Head Sprayer.

Sistem Smart Green House ini berhasil membudidayakan tauge dengan panjang tiga sampai lima sentimeter, tidak mengalami perubahan warna, dan tauge bisa dipanen tanpa ekor.

Keywords: Arduino, otomasi, penyiraman, tauge

\section{PENDAHULUAN}

Tauge merupakan kecambah yang berasal dari biji kacang hijau yang tumbuh dengan memiliki bagian putih dan panjang hingga sembilan sentimeter. Tauge merupakan jenis sayuran umum yang mudah dikonsumsi, mudah diperoleh, memiliki harga yang terjangkau, mengandung banyak senyawa fitokimiawi yang berkhasiat, dan tidak menghasilkan senyawa berefek buruk [1].

Masa pertumbuhan tauge adalah tiga hari dengan minimal dua kali penyiraman dalam sehari dan bisa dipanen pada hari keempat [7]. Dibutuhkan sebuah metode yang tepat agar tauge dapat tumbuh dengan panjang antara 3 
hingga 5 sentimeter dan tidak mengalami perubahan warna yang berarti atau mengalami gagal pertumbuhan karena terpapar cahaya berlebih [13]. Metode budidaya tauge yang ada ditengarai masih memiliki kekurangan, yaitu membutuhkan campur tangan manusia dalam berbagai faktor, seperti melakukan penyiraman secara berkala sesuai siklus penyiraman dan pemotongan tauge. Penyiraman secara berkala yang dilakukan secara manual berpotensi menyebabkan kesalahan karena lupa menyiram. Dari segi waktu pemangkasan, untuk jumlah besar pemotongan bagian ekor tauge membutuhkan waktu yang lama. Selain itu, ada beberapa masalah lain seperti penentuan lokasi ideal untuk budidaya tauge, dan deteksi kebocoran atau genangan air. Dengan demikian, muncul suatu urgensi untuk merancang sebuah sistem yang mampu memberikan solusi bagi budidaya tauge atau kecambah dengan panjang antara 3 hingga 5 sentimeter dan tanpa mengalami perubahan warna, penyiraman otomatis sesuai dengan siklus penyiraman, dan pemotongan bagian ekor tauge saat panen.

Penelitian untuk menerapkan dan mengembangkan otomasi pada bidang agrikultur sudah banyak dilakukan sejak memasuki millennium baru [6]. [16] berhasil mengembangkan sistem penyuplai air minum untuk kandang unggas menggunakan mikrokontroler Arduino untuk memonitor dan mengendalikan suplai air secara otomatis agar setiap kandang unggas menerima volume air yang sama. [8] berhasil mengembangkan sistem monitoring dan otomasi pada domain agrikultur menggunakan teknologi IoT (Internet of Things) yang ditujukan untuk meningkatkan efisiensi penggunaan air dan mengurangi biaya tenaga kerja. [17] berhasil mengembangkan otomasi untuk irigasi sawah menggunakan pendekatan IoT dan machine learning untuk mengatur penggunaan air untuk mengatasi masalah erosi tanah, irigasi berlebih dan masalah irigasi pada jenis tanaman tertentu.

Penelitian ini difokuskan kepada rancang bangun suatu sistem budidaya tauge secara otomatis dengan mengintegrasikan sensor pendukung dan mikrokontroler. Sistem semacam ini selanjutnya akan disebut sebagai Sistem Smart Green House. Untuk dapat berfungsi sebagaimana mestinya, sistem ini menggunakan beberapa sensor. Pertama, sensor pendeteksi cahaya (menggunakan light dependent resistor GL5506) yang digunakan untuk menentukan lokasi budidaya agar tauge tidak mengalami perubahan warna. Kedua, sensor pendeteksi air (menggunakan water sensor Funduino dan buzzer) untuk memberikan peringatan kebocoran air di tempat sekitar. Ketiga, sensor ketinggian air (menggunakan ultrasonic ping HC-SR04) untuk mengisi air kembali di tempat penyimpanan air. Sensor keempat adalah sensor suhu dan kelembaban (menggunakan humidity and temperature sensor DHT11) yang digunakan untuk menjaga tauge pada kondisi ideal. Pada sistem ini juga digunakan pompa air untuk kebutuhan penyiraman dengan durasi dan jadwal waktu yang ditentukan sesuai siklus penyiraman agar tauge mendapat nutrisi untuk bisa bertumbuh dengan panjang 3 hingga 5 sentimeter. Sistem ini menggunakan kain tertentu untuk mendapatkan tauge yang bisa dipotong bagian ekornya saat panen. Mikrokontroler yang digunakan dalam sistem ini adalah Arduino Mega 2560.

Penampakan luar dari Sistem Smart Green House berupa sebuah wadah berbentuk balok yang terbuat dari lembaran akrilik. Untuk membuka lembaran akrilik di sisi atas digunakan sebuah motor servo yang arah putarnya dikendalikan oleh sebuah potentiometer. Sementara sistem penyiraman otomatis bekerja dengan menggabungkan relay dan pompa $12 \mathrm{~V}$, menghubungkan pipa-pipa berukuran diameter $8 \mathrm{~mm}$ menggunakan konektor pipa (knee dan nipple) dan melengkapi pipa dengan mata penyiram, yaitu fogger head sprayer.

\section{METODE PENELITIAN}

Metode penelitian yang digunakan pada penelitian ini adalah studi kepustakaan, eksperimentasi, dan pengembangan aplikasi. Mengingat pentingnya pemahaman yang cukup mengenai karakteristik tauge, kondisi ideal dan budidayanya, maka studi kepustakaan seputar subyek tersebut dilakukan secara intensif. Selain itu dilakukan juga studi kepustakaan mengenai berbagai perangkat keras dan peranti lunak yang dibutuhkan untuk keperluan pembangunan sistem Smart Green House ini. Secara khusus dilakukan studi kepustakaan atas spesifikasi dan cara menggunakan mikrokontroler Arduino beserta pemrogramannya, di samping dipelajari juga karateristik dan kerja sensor cahaya, sensor 
pendeteksi air, sensor ketinggian permukaan air, serta sensor suhu dan kelembaban.

Dengan dibekali pengetahuan yang cukup mengenai perangkat keras dan peranti lunak yang akan digunakan, sejumlah eksperimen dilakukan. Pertama-tama, untuk mengetahui respon atau kerja tiap sensor saat sensor mendeteksi suatu stimulan, eksperimen menggunakan berbagai sensor yang ada dilakukan. Eksperimen ini dilakukan untuk memeriksa fungsionalitas masing-masing sensor saat diterapkan berbagai kondisi operasional atau dikenai berbagai pemicu eksternal. Selain sensor, eksperimen menggunakan berbagai perangkat untuk keperluan penyiraman air juga dilakukan. Untuk mendapatkan volume air yang tepat dalam durasi penyiraman yang ada, dilakukan berbagai penyesuaian atau pengaturan debit atau banyaknya air yang keluar dari kepala air sebagai hasil dari dorongan air yang mengalir karena pemompaan dari reservoir.

Eksperimen berikutnya yang vital adalah mendapatkan tauge dengan panjang antara 3 hingga 5 sentimeter melalui penyiraman secara berkala di dalam ruangan Smart Green House. Kriteria target lainnya adalah tauge tidak mengalami perubahan warna dan ekor tauge dapat dipotong saat panen. Berkaitan dengan hal itu desain dari rangkaian pipa sebagai jalur air yang mengalir akibat dari kerja pompa air yang ada juga dipertimbangkan.

Setelah eksperimen secara unit, selanjutnya dilakukan eksperimen yang melibatkan integrasi antara berbagai sensor dan subsistem penyiraman air. Kelakuan sistem dan interdependensi antar kelakuan diekspresikan dalam ujud program yang disusun menggunakan IDE Arduino yang tersedia. Program yang disimpan dalam flash memory Arduino tersebut akan dieksekusi kemudian menggunakan bantuan SRAM (static random access memory).

\section{Budidaya Tauge}

Tauge akan tumbuh jika benih mendapat air selama durasi tertentu sesuai dengan siklus penyiraman, yaitu minimal dua kali selama tiga hari. Pemanenan tauge dapat dilakukan pada hari keempat.

Tauge akan tumbuh secara optimal pada suhu antara $23{ }^{\circ} \mathrm{C}$ dan $28{ }^{\circ} \mathrm{C}$ dengan tingkat kelembaban antara $85 \%$ sampai $90 \%$ dan ditempatkan dalam ruangan yang gelap atau tidak terpapar cahaya matahari secara langsung [7].

Untuk mendapatkan tauge dengan panjang antara 3 hingga 5 sentimeter, penelitian ini melakukan eksplorasi pada metode budidaya tauge dalam rumah kaca (green house). Rumah kaca atau green house adalah bangunan yang berbentuk rumah yang dinding dan atapnya terbuat dari material kaca. Rumah kaca digunakan untuk keperluan menanam sayuran, buah-buahan, bunga dan lain sebagainya. Fungsi utama rumah kaca adalah menangkap cahaya matahari sehingga panas akan terperangkap di dalam bangunan, sehingga bagian dalam rumah kaca akan mengalami kenaikan suhu akibat radiasi elektromagnetik dari matahari [12].

Metode budidaya tauge yang digunakan pada penelitian ini menggunakan metode yang dikembangkan oleh Suranto (2016) dengan beberapa modifikasi. Metode tersebut menggunakan kain flanel sebagai media tanam untuk benih kacang hijau agar air tersimpan dalam kain dan benih bisa mendapat air dari kain. Selain itu digunakan kain strimin yang memiliki lubang sebagai tempat dimana bagian ekor akan bertumbuh, dan keranjang surat sebagai tempat untuk air dapat mengalir ke bawah. Penyiraman dilakukan secara berkala pada kain flanel secara merata. Tauge akan tumbuh melalui kain strimin, dan setelah tauge dipanen, proses pengguntingan ekor dapat dilakukan di atas kain strimin dengan menggunting ke seluruh area di kain flanel sehingga didapatkan tauge tanpa bagian ekor.

\section{Komponen Elektronik}

Berbagai komponen elektronik digunakan pada penelitian ini untuk melakukan otomasi pada proses pertumbuhan tauge. Arduino Mega 2560 adalah papan pengembangan elektronika yang menggunakan chip ATmega 2560. Papan mikrokontroller ini memiliki pin I/O sebanyak 54 buah pin digital yang setiap pinnya dapat menghasilkan dan menerima arus maksimal sebesar $40 \mathrm{~mA}, 16$ pin analog input dan 4 pin UART (Universal Asynchronous Receiver Transmitter) [2].

Light Dependent Resistor GL5506 digunakan sebagai sensor cahaya pada sistem ini. Light Dependent Resistor adalah salah satu jenis resistor yang disebut sebagai fotoresistor. Resistansi dari sensor ini berubah-ubah 
tergantung pada intensitas cahaya yang diterima olehnya. Umumnya resistansi kegelapan dari sensor ini adalah 1.000.000 Ohm [14].

Water Sensor Funduino adalah sensor yang digunakan untuk mendeteksi adanya air. Sensor ini memiliki serangkaian konduktor paralel yang dapat mendeteksi air. Sensor bekerja dengan mendeteksi air pada lempengan dan mengirimkan data ke mikrokontroler [4].

Ultrasonic Ping HC-SR04 adalah sensor sonar yang berfungsi untuk menentukan jarak berdasarkan prinsip pantulan gelombang suara dan dipakai untuk mendeteksi keberadaan objek, frekuensi kerja berada di daerah atas frekuensi gelombang suara, dari $40 \mathrm{KHz}$ sampai $400 \mathrm{KHz}$. Sensor ultrasonik ini terdiri dari pemancar atau Chirp dan penerima atau Echo. Jarak minimum dan maksimum yang dapat diukur adalah dua sentimeter hingga empat meter [5].

DHT11 Temperature and Humidity Sensor adalah salah satu jenis sensor yang dapat mengukur dua parameter lingkungan sekitarnya, yaitu suhu dan kelembaban [11].

Liquid Crystal Display atau LCD merupakan tampilan dari bahan cairan kristal yang pengoperasiannya menggunakan sistem dot matriks. LCD banyak digunakan sebagai tampilan dari alat-alat elektronik seperti kalkulator, smartphone atau jam digital. LCD yang digunakan pada penelitian ini adalah LCD $16 \times 2$ yang memiliki 16 kolom dan 2 baris untuk tampilan layar [9].

Buzzer adalah komponen elektronika yang memiliki fungsi untuk mengubah getaran arus listrik menjadi getaran suara. Buzzer memiliki kumparan yang terpasang pada diafragma untuk menghasilkan bunyi, umumnya digunakan sebagai indikator proses [10]. Pada penelitian ini buzzer digunakan untuk mendeteksi genangan air yang keluar dari media tanam.

Sistem ini memiliki sistem pengunci menggunakan potentiometer dan servo motor. Potentiometer adalah adalah komponen elektronik yang nilai resistansinya dapat diatur menggunakan sebuah dial pemutar, dan dapat difungsikan sebagai pembagi tegangan. Servo Motor SG90 adalah sebuah Servo motor berukuran kecil dan ringan yang memiliki tenaga output yang besar, mampu berputar sampai 180 derajat, beroperasi dengan tegangan $5 \mathrm{~V}$ dan suhu antara $0-55^{\circ} \mathrm{C}[3]$.
Relay digunakan untuk mengendalikan perangkat listrik yang lebih besar dan memerlukan tegangan kecil untuk mengaktifkannya [15]. Pada penelitian ini relay digunakan untuk mengendalikan sebuah pompa air $12 \mathrm{~V}$ dari mikrokontroler Arduino.

Untuk melakukan penyiraman supaya tauge dapat disiram secara merata, pompa air dihubungkan dengan fogger head sprayer sebanyak 24 buah menggunakan rangkaian pipa air. Fogger head sprayer berfungsi untuk menyemprotkan air dari pipa ke kain strimin. Pipa air yang digunakan memiliki diameter 8 $\mathrm{mm}$, diameter luar $11 \mathrm{~mm}$ dan panjang 2 meter. Rankgaian pipa air dibuat dengan knee dan nipple system. Knee berfungsi untuk menyambungkan dua pipa dari satu sisi ke sisi lain, dan nipple berfungsi untuk menyambungkan tiga sisi pipa.

\section{Desain Penelitian}

Perancangan maket dari Sistem Smart Green House diperlihatkan pada gambar 1.

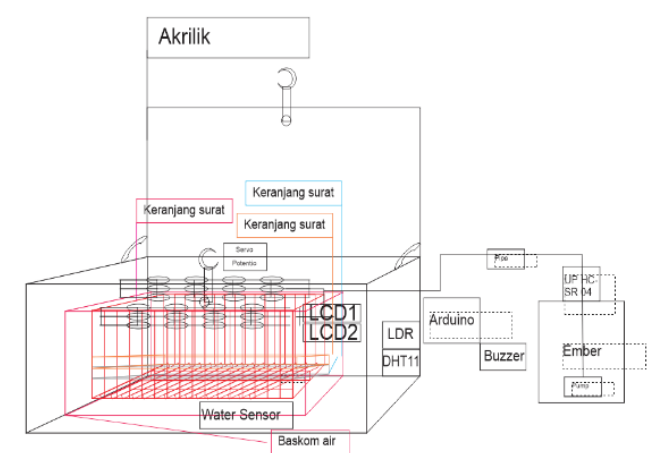

Gambar 1. Rancangan maket Smart Green House

Perancangan sistem penyiraman air diperlihatkan pada Gambar 2. 


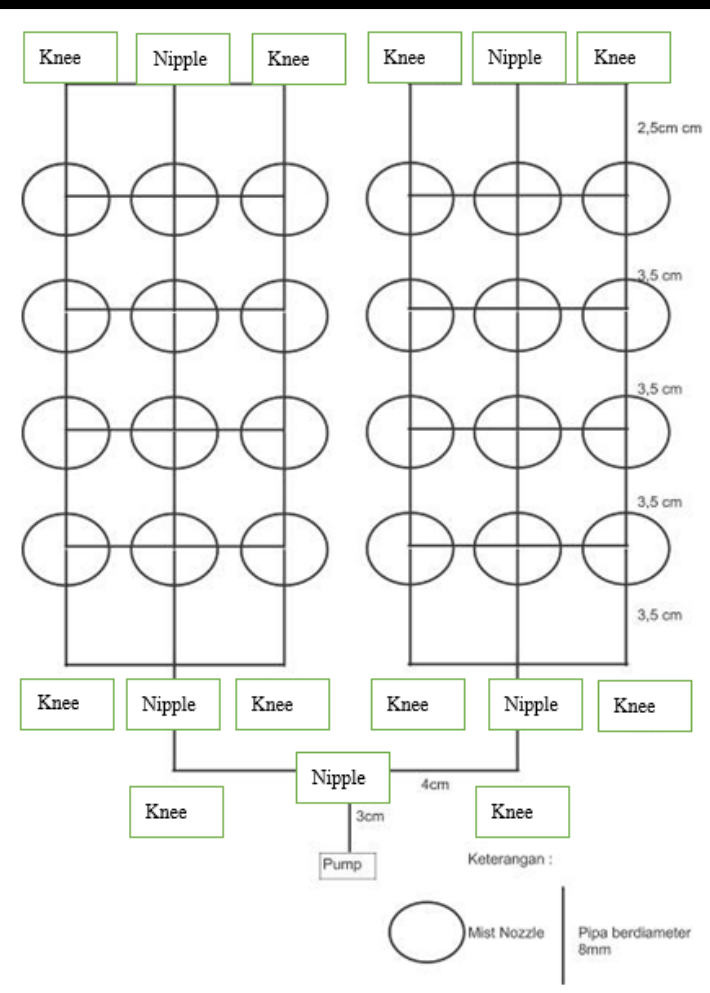

Gambar 2. Sistem Penyiraman Air

Diagram blok sistem diperlihatkan pada gambar 3.

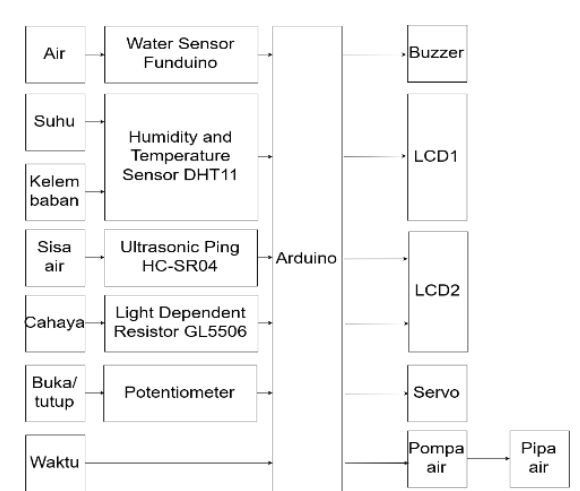

Gambar 3. Diagram Blok Sistem Smart Green House

Diagram alir sistem diperlihatkan pada gambar 4.

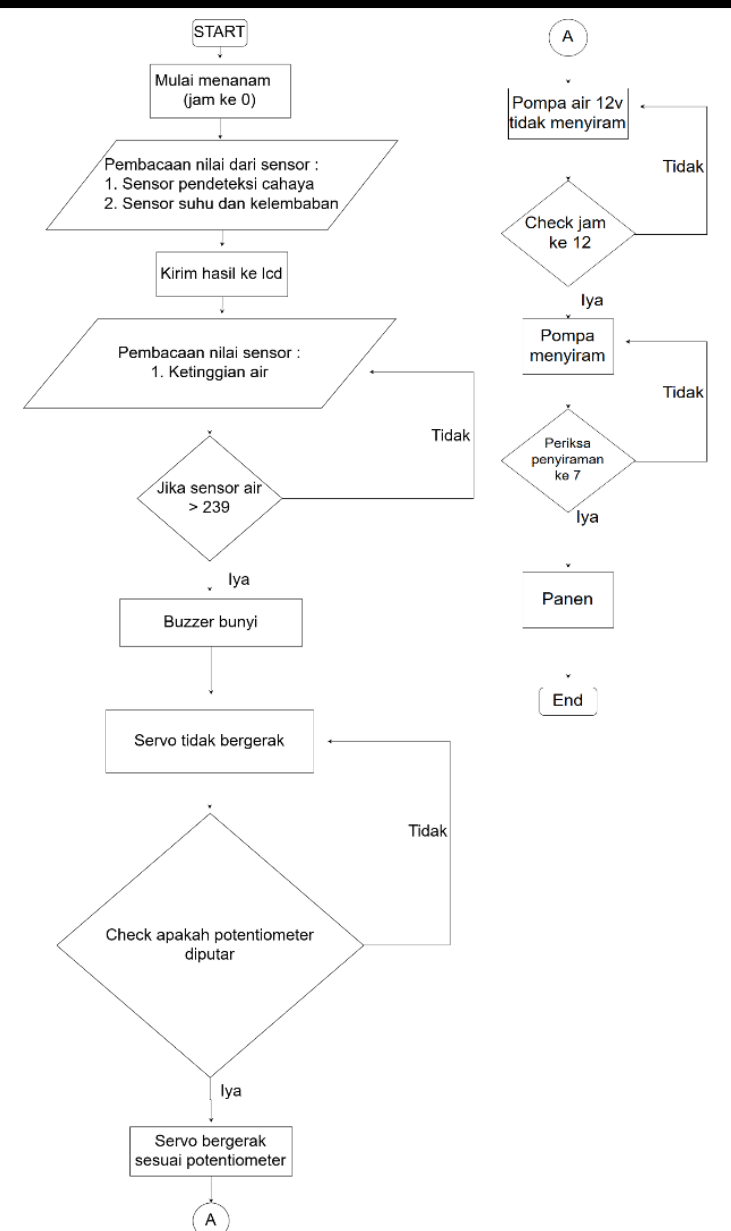

Gambar 4. Diagram Alur Kerja Penyiraman Air Otomatis

\section{HASIL DAN PEMBAHASAN}

Pada bagian ini akan dilakukan pengujian komponen dan pembahasan hasil pengujian. Pengujian komponen dilakukan dengan tujuan untuk mengetahui apakah sensor berfungsi dengan baik, mengetahui nilai dari fungsi sensor serta mengintegrasikan sensor dengan metode budidaya yang dipakai. Pengujian yang dilakukan adalah sebagai berikut:

\section{Pengujian Penentuan Lokasi Sistem dengan Light Dependent Resistor GL5506}

Pengujian dilakukan di tiga tempat dan waktu yang berbeda pada tanggal 7 April 2019, dengan tujuan untuk mengetahui tempat yang ideal untuk meletakkan Sistem Smart Green House. Untuk menumbuhkan tauge diperlukan tempat dengan tingkat intensitas cahaya terdeteksi kurang dari $1 \%$. Hasil pengujian dapat dilihat pada Tabel 1. 
Tabel 1. Pengujian Light Dependent Resistor GL5506

\begin{tabular}{|c|c|c|c|c|}
\hline \multirow{2}{*}{ No } & Lokasi & Waktu & \multicolumn{2}{|c|}{ Hasil Pengujian } \\
\cline { 4 - 5 } & Pengujian & Pengujian & Tingkat Intensitas Cahaya & Keterangan \\
\hline 1 & Dapur & $08: 11$ & $2 \%$ & Tidak Cocok \\
\hline 2 & Dapur & $08: 23$ & $2 \%$ & Tidak Cocok \\
\hline 3 & Dapur & $08: 32$ & $3 \%$ & Tidak Cocok \\
\hline 4 & Toilet Lantai 1 & $11: 31$ & $5 \%$ & Tidak Cocok \\
\hline 5 & Toilet Lantai 1 & $11: 44$ & $3 \%$ & Tidak Cocok \\
\hline 6 & Toilet Lantai 1 & $11: 51$ & $4 \%$ & Tidak Cocok \\
\hline 7 & Toilet Lantai 2 & $15: 27$ & $1 \%$ & Cocok \\
\hline 8 & Toilet Lantai 2 & $15: 44$ & $1 \%$ & Cocok \\
\hline 9 & Toilet Lantai 2 & $15: 51$ & $1 \%$ & Cocok \\
\hline
\end{tabular}

Dari Tabel 1 dapat disimpulkan bahwa tingkat intensitas cahaya yang ideal untuk menumbuhkan tauge dapat ditemukan pada lokasi Toilet lantai 2.

\section{Pengujian Penentuan Lokasi Sistem dengan Temperature and Humidity Sensor DHT11}

Pengujian Temperature and Humidity Sensor DHT11 dilakukan di tiga tempat dan waktu yang berbeda pada tanggal 7 April 2019 dengan tujuan untuk mengetahui tempat yang ideal untuk meletakkan Sistem Smart Green House. Untuk menumbuhkan tauge diperlukan tempat dengan suhu yaitu $23{ }^{\circ} \mathrm{C}$ sampai dengan $28{ }^{\circ} \mathrm{C}$ dan tingkat kelembaban diantara $85 \%$ sampai $90 \%$. Hasil pengujian dapat dilihat pada Tabel 2.

Tabel 2. Pengujian Temperature and Humidity Sensor DHT11

\begin{tabular}{|c|c|c|c|c|c|}
\hline No & Lokasi & Waktu & \multicolumn{3}{|c|}{ Hasil Pengujian } \\
\cline { 4 - 6 } & Pengujian & Pengujian & Suhu $\left({ }^{\circ} \mathrm{C}\right)$ & Kelembaban (\%) & Keterangan \\
\hline 1 & & & & & \\
\hline 2 & Dapur & $08: 11$ & 21 & 80 & Tidak Cocok \\
\hline 3 & Dapur & $08: 23$ & 23 & 75 & Tidak Cocok \\
\hline 4 & Toilet Lantai 1 & $08: 32$ & 22 & 79 & Tidak Cocok \\
\hline 5 & Toilet Lantai 1 & $11: 31$ & 21 & 91 & Tidak Cocok \\
\hline 6 & Toilet Lantai 1 & $11: 51$ & 22 & 93 & Tidak Cocok \\
\hline 7 & Toilet Lantai 2 & $15: 27$ & 25 & 91 & Tidak Cocok \\
\hline 8 & Toilet Lantai 2 & $15: 44$ & 26 & 86 & Cocok \\
\hline 9 & Toilet Lantai 2 & $15: 51$ & 25 & 87 & Cocok \\
\hline
\end{tabular}

Berdasarkan data yang disajikan dalam Tabel 2, tingkat suhu dan kelembaban ideal untuk menumbuhkan tauge dapat ditemukan pada lokasi Toilet Lantai 2. Apabila digabungkan dengan hasil pada tabel 1 dapat disimpulkan bahwa lokasi Toilet Lantai 2 dapat digunakan untuk menumbuhkan tauge karena memiliki tingkat intensitas cahaya, suhu dan kelembaban yang ideal.

\section{Pengujian Sensor Air dan Buzzer}

Pengujian water sensor Funduino dilakukan dengan memasukkan sensor dua kali ke dalam air selama tiga detik, untuk mengetahui nilai yang terbaca pada Arduino Serial Monitor sebagai indikator terdeteksinya air untuk menyalakan buzzer. Hasil pembacaan sensor dapat dilihat pada Tabel 3.

Tabel 3. Pengujian Sensor Air

\begin{tabular}{|c|c|c|}
\hline Pengujian Ke & Detik Ke & Hasil Pembacaan Sensor \\
\hline 1 & 1 & 258 \\
\hline 1 & 2 & 239 \\
\hline 1 & 3 & 258 \\
\hline 2 & 1 & 298 \\
\hline 2 & 2 & 304 \\
\hline 2 & 3 & 300 \\
\hline
\end{tabular}

Dari tabel 3, dapat disimpulkan bahwa batas bawah untuk membunyikan buzzer dapat diset pada level 239. Apabila sensor air mendeteksi tingkat air diatas 239, buzzer akan menyala.

\section{Pengujian Ketinggian Air dengan HC-SR04 Ping Sensor}

Pengujian sensor dilakukan sebanyak tiga kali. Pengujian pertama dilakukan dengan menghadapkan sensor ke lantai dan dibandingkan dengan pengukuran dari sebuah penggaris. Pengujian kedua dilakukan pada air di dalam ember dengan ketinggian air yang berbeda, dan pengujian ketiga dilakukan pada air di dalam ember dengan ketinggian air yang sama. Untuk pengukuran dengan ember digunakan penggaris untuk menentukan batas ideal untuk pengisian air. Tinggi ember adalah tiga puluh tiga sentimeter. Ketinggian air dibagi tiga kategori, yaitu 0-16 cm (fill, perlu diisi), $17-20 \mathrm{~cm}$ (half, setengah terisi), dan $21-33 \mathrm{~cm}$ (full, hampir penuh). Hasil pengujian dapat dilihat pada Tabel 4 di bawah.

Tabel 4. Pengujian Ketinggian Air

\begin{tabular}{|c|c|c|}
\hline Pengujian Ke & Ketinggian $(\mathrm{cm})$ & Keterangan \\
\hline 1 & $0-16$ & Fill \\
\hline 1 & $17-20$ & Half \\
\hline 1 & $21-33$ & Full \\
\hline 2 & 15 & Fill \\
\hline 2 & 20 & Half \\
\hline 2 & 21 & Full \\
\hline 3 & 15 & Fill \\
\hline 3 & 15 & Fill \\
\hline 3 & 15 & Fill \\
\hline
\end{tabular}

Berdasarkan tabel 4, dapat disimpulkan bahwa sensor bekerja dengan baik untuk mendeteksi ketinggian air. 


\section{Pengujian Sistem Pengunci}

Pengujian ini dilakukan untuk menguji sistem pengunci untuk mengamankan Smart Green House agar tidak dibuka secara sembarangan. Sistem pengunci terdiri dari sebuah potentiometer dan servo motor yang dipasang seperti pada Gambar 5. Hasil pengujian dapat dilihat pada Tabel 5 .

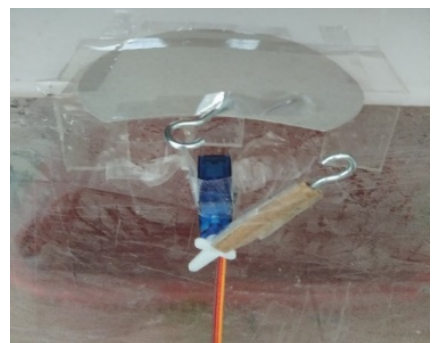

Gambar 5. Sistem Pengunci

Tabel 5. Pengujian Sistem Pengunci

\begin{tabular}{|l|l|l|l|l|}
\hline Pemutaran & Posisi & Kondisi Servo & Keterangan & Delay \\
\hline 1 & Dari kiri ke atas & Tidak bisa & Tidak bergerak & 2 detik \\
\hline 2 & Dari atas ke kanan & Mengikuti & Terbuka & 1 detik \\
\hline 3 & Dari kanan ke atas & Mengikuti & Tertutup & 1 detik \\
\hline 4 & Dari atas ke kiri & Tidak mengikuti & Tidak bergerak & 1 detik \\
\hline 5 & Dari kiri ke atas & Tidak bisa & Tidak bergerak & 2 detik \\
\hline 6 & Dari atas ke kanan & Mengikuti & Terbuka & 1 detik \\
\hline 7 & Dari kanan ke atas & Mengikuti & Tertutup & 2 detik \\
\hline 8 & Dari atas ke kiri & Tidak mengikuti & Tidak bergerak & 2 detik \\
\hline
\end{tabular}

Berdasarkan hasil dari tabel 5, sistem hanya akan tertutup apabila potentiometer diputar dari arah kanan ke atas, dan hanya akan terbuka apabila potentiometer diputar dari atas ke kanan, dengan delay sekitar 1-2 detik.

\section{Pengujian Penyiraman Tauge}

Pengujian dilakukan dengan melakukan penyiraman dengan pompa air pada waktuwaktu yang sudah ditentukan. Masing-masing penyiraman dilakukan dengan durasi 10 detik. Pengujian dilakukan pada tanggal 7 April 2019 pada waktu-waktu yang berbeda. Hasil pengujian dapat dilihat pada tabel 6 .
Tabel 6. Pengujian Penyiraman Tauge

\begin{tabular}{|c|c|c|c|}
\hline Pengujian Ke & Waktu Awal & Waktu Akhir & Durasi Penyiraman \\
\hline 1 & $09: 15: 17$ & $09: 15: 27$ & $10.000 \mathrm{~ms} / 10$ detik \\
\hline 2 & $09: 15: 27$ & $09: 15: 37$ & $10.000 \mathrm{~ms} / 10$ detik \\
\hline 3 & $09: 15: 37$ & $09: 15: 47$ & $10.000 \mathrm{~ms} / 10$ detik \\
\hline 4 & $11: 29: 01$ & $11: 29: 11$ & $10.000 \mathrm{~ms} / 10$ detik \\
\hline 5 & $11: 29: 21$ & $11: 29: 31$ & $10.000 \mathrm{~ms} / 10$ detik \\
\hline 6 & $11: 29: 41$ & $11: 29: 51$ & $10.000 \mathrm{~ms} / 10$ detik \\
\hline 7 & $13: 37: 02$ & $13: 37: 12$ & $10.000 \mathrm{~ms} / 10$ detik \\
\hline 8 & $13: 37: 22$ & $13: 37: 32$ & $10.000 \mathrm{~ms} / 10$ detik \\
\hline 9 & $13: 37: 42$ & $13: 37: 52$ & $10.000 \mathrm{~ms} / 10$ detik \\
\hline 10 & $19: 48: 05$ & $19: 48: 15$ & $10.000 \mathrm{~ms} / 10$ detik \\
\hline 11 & $19: 48: 25$ & $19: 48: 35$ & $10.000 \mathrm{~ms} / 10$ detik \\
\hline 12 & $19: 48: 45$ & $19: 48: 55$ & $10.000 \mathrm{~ms} / 10$ detik \\
\hline 13 & $21: 58: 09$ & $21: 58: 19$ & $10.000 \mathrm{~ms} / 10$ detik \\
\hline 14 & $21: 58: 29$ & $21: 58: 39$ & $10.000 \mathrm{~ms} / 10$ detik \\
\hline 15 & $21: 58: 49$ & $21: 58: 59$ & $10.000 \mathrm{~ms} / 10$ detik \\
\hline
\end{tabular}

Berdasarkan tabel 6, dapat disimpulkan bahwa tingkat keberhasilan penyiraman menggunakan pompa air $12 \mathrm{~V}$ adalah $100 \%$.

\section{Pengujian Budidaya Tauge}

Pada pengujian ini dilakukan proses pembudidayaan tauge dari awal hingga akhir menggunakan sistem Smart Green House secara keseluruhan. Pertumbuhan tauge dipantau setiap terjadi penyiraman, yaitu dua kali sehari selama tiga hari dan satu kali pada hari keempat, kemudian tauge dipanen. Pengujian dilakukan dari tanggal 15-18 Mei 2019. Hasil pengujian dapat dilihat pada tabel 7.

Tabel 7. Pengujian Pembudidayaan Tauge

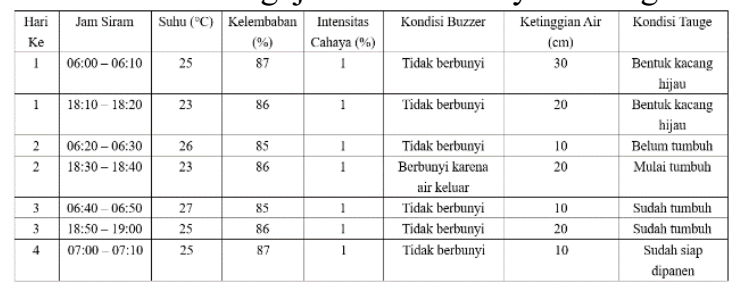

Berdasarkan tabel 7, dapat disimpulkan bahwa sistem bekerja dengan baik dalam proses budidaya tauge. Sensor suhu, temperatur dan cahaya memantau bahwa kondisi ideal tetap terjaga dalam proses pembudidayaan. Buzzer berbunyi satu kali karena terdeteksi air keluar dari media tanam. Sensor ketinggian air berhasil menunjukkan perubahan ketinggian air setiap terjadi penyiraman.

\section{Pengujian pengukuran Panjang Tauge}

Pengujian ini dilakukan untuk mengukur rata-rata panjang tauge yang berhasil tumbuh dan dipanen dari tabel 7, untuk menentukan apakah rata-rata panjang tauge yang dihasilkan oleh sistem memenuhi syarat atau tidak. 
Pengujian dilakukan dengan mengukur panjang dari lima puluh tauge yang dihasilkan menggunakan penggaris, dan hasilnya dicatat pada tabel 8 .

Tabel 8. Hasil Pengukuran Panjang Tauge

\begin{tabular}{|c|c|}
\hline Jumlah Tauge & Panjang $(\mathrm{cm})$ \\
\hline 6 & 3 \\
\hline 8 & 3,5 \\
\hline 14 & 4 \\
\hline 12 & 4,5 \\
\hline 10 & 5 \\
\hline
\end{tabular}

Kisaran panjang tauge sudah memenuhi tujuan penelitian yang ditetapkan, yaitu menghasilkan tauge dengan panjang antara tiga sampai lima sentimeter tanpa bagian ekor. Untuk mendapatkan rata-rata panjang tauge, digunakan rumus berikut:

$$
\hat{x}=\frac{\Sigma\left(f_{\underline{R}} \cdot x_{\underline{i}}\right)}{n}
$$

Dimana $f_{i}=$ frekuensi ke-i, $x_{i}=$ data ke-i, dan $\mathrm{n}=$ total frekuensi. Dengan demikian, ratarata panjang tauge dapat dihitung dengan memasukkan $n=50$ dan menggunakan nilai $f_{i}$ dan $\mathrm{x}_{\mathrm{i}}$ yang didapat dari tabel 7 pada rumus (1). Rata-rata $=$

$$
\begin{aligned}
((6 \times 3)+ & (8 \times 3,5)+(14 \times 4)+(12 \times 4.5)+(10 \times 5)) / 50 \\
& =(18+28+56+54+50) / 50 \\
& =4.12 \mathrm{~cm}
\end{aligned}
$$

\section{SIMPULAN DAN SARAN}

Dari hasil dan pembahasan sistem yang telah dilakukan, dapat disimpulkan bahwa sistem dapat menumbuhkan tauge dengan kisaran panjang antara $3-5 \mathrm{~cm}$ dan panjang ratarata $4.12 \mathrm{~cm}$ tanpa bagian ekor selama empat hari. Sistem dapat diamankan dengan sistem pengunci menggunakan potentiometer dan servo motor. Pompa air berhasil melakukan penyiraman sebanyak tujuh kali selama empat hari. Sensor pendeteksi cahaya, sensor suhu dan kelembaban dapat digunakan untuk menentukan lokasi ideal untuk melakukan budidaya tauge, dan memberikan data yang akurat selama proses budidaya. Sensor air berhasil mendeteksi dan membunyikan buzzer saat terdeteksi adanya genangan air pada media tanam. Sensor ketinggian air berhasil memberikan data ketinggian air yang akurat selama proses budidaya berlangsung. Secara keseluruhan, sistem dinilai dapat membantu untuk melakukan budidaya tauge tanpa harus melibatkan banyak campur tangan manusia dalam proses budidaya.
Beberapa saran untuk pengembangan pada penelitian selanjutnya antara lain adalah menggunakan data logging seperti ThingSpeak untuk mencatat data pembacaan sensor sehingga dapat dipantau secara real time. Buzzer dapat diintegrasikan dengan sensor lain supaya dapat berbunyi saat terdeteksi kondisi yang tidak sesuai dengan kondisi ideal. Sistem pengunci dengan potentiometer dapat diganti menggunakan komponen lain seperti keypad untuk meningkatkan keamanan sistem. Komponen modul Real Time Clock RTC 3231 dapat digunakan sebagai pengganti untuk pewaktu sistem. Kipas angin dapat diintegrasikan dengan sensor suhu dan kelembaban untuk menjaga suhu ideal.

\section{DAFTAR PUSTAKA}

[1] Alodokter. (2018). Di Balik Manfaat Toge, Kenali Bahaya dan Cara Mengonsumsinya. Diakses tanggal 6 Juni 2019, dari https://www.alodokter.com/di-balikmanfaat-toge-kenali-bahaya-dan-caramengonsumsinya

[2] Arduino (2018). Getting Started With Arduino Mega 2560. Diakses tanggal 26 Februari 2021, dari https://www.arduino.cc/en/Guide/Arduino Mega2560

[3] Components101. (2017). Servo Motor SG90. Diakses 29 Juni 2019, dari https://components101.com/servo-motorbasics-pinout-datasheet

[4] Curtocircuito. (2013). Water Sensor Module User's Manual. Diakses 26 Februari 2021, dari

https://curtocircuito.com.br/datasheet/senso r/nivel_de_agua_analogico.pdf

[5] Harahap, M.R. (2017). Rancang Bangun Pendeteksi Dan Notifikasi Banjir Menggunakan Logika Fuzzy Dan Media Sosial Sebagai Sumber Informasi. Other thesis, Politeknik Negeri Sriwijaya.

[6] Kassler, M. (2001). Agricultural Automation in the new Millennium. Computers and Electronics in Agriculture, 30(1-3), 
https://doi.org/10.1016/S01681699(00)00167-8

[7] Lal, G., Shanmugasundaram, S. (2001). Mungbean Sprout Production. AVDRC Training Guide, AVDRC

[8] Mohanraj, I., Ashokumar, K., Naren, J. (2016). Field Monitoring and Automation Using IOT in Agriculture Domain. Procedia Computer Science, 93(2016), 931-939, https://doi.org/10.1016/j.procs.2016.07.275

[9] Nyebarilmu. (2017). Cara mengakses modul display 16x2. Diakses 26 Februari 2021, dari https://www.nyebarilmu.com/caramengakses-modul-display-lcd-16x2/

[10] Nyebarilmu. (2017). Tutorial Arduino Mengakses Buzzer. Diakses 26 Februari 2021, https://www.nyebarilmu.com/tutorialarduino-mengakses-buzzer/

[11] Saptaji. (2016), Mengukur Suhu dan Kelembaban Udara dengan Sensor DHT11 dan Arduino. Diakses 4 April 2019, dari http://saptaji.com/2016/08/10/mengukursuhu-dan-kelembaban-udara-dengansensor-dht11-dan-arduino

[12] StudioBelajar. (2019). Efek Rumah KacaPengertian dan Proses Terjadinya. Diakses 10 Mei 2019, dari https://www.studiobelajar.com/efek-rumahkaca/

[13] Suranto, B. (2016). How to Make Mung Bean Sprouts. Diakses 10 Januari 2021, dari https://www.youtube.com/watch?v=Lp6Nn Ymi3is\& $=299 \mathrm{~s}$

[14] Teknik Elektronika. (2019). Pengertian LDR (Light Dependent Resistor) dan Cara Mengukurnya. Diakses 20 Februari 2019, dari

https://teknikelektronika.com/pengertianldr-light-dependent-resistor-caramengukur-ldr/

[15] Teknik Elektronika. (2019). Pengertian Relay dan Fungsinya. Diakses 12 April 2019, dari https://teknikelektronika.com/pengertianrelay-fungsi-relay/

[16] Tjoa, G.W., Aribowo, A., Putra, A.S. (2019). Design of Automatic Drinking Water Supply System for Poultry Cage. $5^{\text {th }}$
International Conference on New Media Studies (CONMEDIA), pp. 115-120, IEEE

[17] Vij, A., Vijendra, S., Jain, A., Bajaj, S., Bassi, A., Sharma, A. (2020). IoT and Machine Learning Approaches for Automation of Farm Irrigation System. Procedia Computer Science, 167(2020), 1250-1257,

https://doi.org/10.1016/j.procs.2020.03.440 